\title{
The Pentane- and Tolvene-Soluble Fractions of a Petroleum Residue and three Coal Tars by Size Exclusion Chromatography and UV-Fluorescence Spectroscopy
}

\author{
F. Karaca' ${ }^{1}$, M. Millan-Agorio' ', T.J. Morgan' ', I.D. Bull' ${ }^{2}$, A.A. Herod' ${ }^{1}$ and R. Kandiyoti ${ }^{1}$ \\ 1 Department of Chemical Engineering, Imperial College London, London SW7 2AZ, UK \\ 2 Department of Chemistry, Bristol University, Bristol, BS8 ITS, UK \\ e-mail: karacaftr@yahoo.com - marcos.millan@imperial.ac.uk -t.j.morgan@imperial.ac.uk - \\ lan.D.Bull@bristol.ac.uk - a.herod@imperial.ac.uk -r.kandiyoti@imperial.ac.uk
}

\begin{abstract}
Résumé - Les fractions solubles dans le pentane et le toluène d'un résidu pétrolier et de trois échantillons de goudron de charbons par chromatographie d'exclusion stérique et par spectroscopie de fluorescence - Un résidu pétrolier de distillation atmosphérique ainsi que trois échantillons de goudron issus des pyrolyses de différents charbons sont séparés en sept fractions par chromatographie liquide sur gel de silice. Les solvants utilisés successivement sont : le pentane, le toluène, l'acétonitrile, la pyridine, la 1-methyl-2-pyrrolidinone (NMP) et l'eau permettant l'obtention de 7 fractions. Les fractions obtenues pour chacun des quatre échantillons sont ensuite comparées par chromatographie d'exclusion stérique (SEC) au moyen d'NMP comme éluant, puis par spectroscopie de fluorescence. Cet article traite uniquement le cas des fractions solubles dans le pentane et le toluène, car étant les moins polaires. D'après les analyses SEC, la taille des molécules aromatiques entre les premières fractions solubles dans le pentane et celles solubles dans le toluène augmente. Ainsi, les fractions du résidu pétrolier possèdent des molécules de plus grande taille que celles extraites, par le même solvant, pour les différents goudrons. Les trois échantillons de goudrons montrent des différences significatives, indiquant que la température de pyrolyse joue un rôle important sur la taille des molécules. Les résultats de spectroscopie, en solution NMP, montrent également de grandes différences entre le résidu pétrolier et les trois goudrons, de même que ces trois derniers sont différents entre eux. En général, les fractions du résidu pétrolier contiennent de plus petits groupes aromatiques que les fractions liquides issues du charbon. Ces fractions de faible polarité, contenant des éléments exclus par la colonne chromatographique, ont peu de chance d'être des agrégats de molécules polaires.
\end{abstract}

Abstract - The Pentane- and Toluene-Soluble Fractions of a Petroleum Residue and three Coal Tars by Size Exclusion Chromatography and UV-Fluorescence Spectroscopy - A petroleum atmospheric pressure distillate residue and three tars derived from different coals using different severities of thermal treatment were separated into seven fractions using column chromatography on silica and sequential elution by the solvent sequence pentane, toluene, acetonitrile, pyridine, 1-methyl-2-pyrrolidinone (NMP) and water. The fractions from the four extractions have been compared using size exclusion chromatography (SEC) in NMP as eluent and by synchronous ultra-violet-fluorescence (UV-F). This paper concerns the pentane and toluene soluble fractions only since these are the least polar fractions. 
By SEC, the size of the aromatic molecules increased from the first pentane soluble fractions to the toluene-soluble fractions, with the petroleum residue fractions of larger size than the equivalent fractions from coal liquids. The three coal tars showed significant differences, indicating that temperature of pyrolysis had a significant effect on the molecular size. Synchronous UV-F spectra of the four sets of fractions, in solution in NMP, again showed significant differences between the petroleum residue and the coal tars, as well as amongst the three coal tars. In general, the petroleum residue fractions contained smaller aromatic clusters than the coal liquid fractions. These low-polarity fractions contained material excluded from the column porosity in SEC that was unlikely to consist of aggregates of polar molecules.

\section{INTRODUCTION}

The ongoing debate about the molecular mass ranges of petroleum fractions has shown marked differences in both results and interpretation between our work $[1,2]$ based on size exclusion chromatography (SEC) using 1-methyl-2pyrrolidinone (NMP) as eluent compared with estimates based on the fluorescence depolarisation technique [3] and the application of FT-ICR -MS [4, 5]. The differences are summarised in two letters to Fuel $[2,3]$. Our work in SEC operates at solution concentrations below any probability of aggregate formation and this has been shown through a variety of reported experiments [1]. In the present work, fractions prepared from a petroleum distillation residue and three coal-derived tars with markedly different thermal histories have been characterized. The fractions obtained from column chromatography on silica were the materials soluble in two sequential elutions of the column using pentane, followed by elution in toluene. Other fractions were obtained using acetonitrile, pyridine, NMP and water. This paper discusses the results for fractions eluted in pentane and in toluene only.

The fractions examined correspond approximately to oils and asphaltenes and the fractions from the petroleum residue are essentially non-polar because of the low oxygen and nitrogen contents. A previous fractionation using silica and six solvents to yield seven fractions (with two aliquots of pentane) has allowed the definition of alkanes by size exclusion chromatography in heptane eluent and by hightemperature GC-MS [6]. This paper presents results from the predominantly aromatic material soluble in NMP contained within the pentane-soluble and toluene-soluble fractions, by size exclusion chromatography (with as NMP eluent) and by UV-fluorescence spectroscopy. The samples have also been compared by high-temperature GC-MS.

\section{EXPERIMENTAL}

\subsection{Samples}

The petroleum atmospheric distillation residue was provided by the Petrox refinery near Concepción (Chile) and has been described previously [7-10]. It was obtained from the bottom of an atmospheric-pressure distillation column, where 70\% of the oil vaporizes while the rest of the feed is treated with a steam counterflow at $370^{\circ} \mathrm{C}$ which removes lighter components of the oil. The present sample is part of the reduced crude which leaves the bottom of the column at about $330^{\circ} \mathrm{C}$.

The coal derived liquids studied were from different coals and include:

- Coal tar pitch: Tar from the high temperature coking of coal is distilled to leave pitch as residue. The present sample is a "soft" pitch, containing some light ends (from anthracene oil), such as phenanthrene. It has been used as our laboratory standard due to its homogeneity, chemical stability and relative abundance. This sample has been investigated extensively [11-14].

- Coal liquefaction extract (coal digest): The coal liquefaction extract $[15,16]$ or coal digest, was from the former British Coal Point of Ayr Coal Liquefaction Pilot Plant: It corresponds to the extracted coal in recycle solvent stream, after filtration of undissolved solids and ash. This sample was of particular interest since it had suffered less thermal degradation than the coal tar pitch.

- Low temperature tar: A low temperature coal oil from the Coalite process $[17,18]$ was an oil produced by low temperature distillation of coal to produce a smokeless solid fuel. This tar suffered the least thermal degradation of the three coal-derived samples.

\subsection{Size Exclusion Chromatography}

SEC using NMP as eluent has been described in detail elsewhere $[1,19]$. The column chromatography fractions of the petroleum residue and the coal liquids were examined using the Mixed-D column (Polymer Laboratories, Church Stretton, UK) at $80^{\circ} \mathrm{C}$ with NMP as eluent to examine aromatics in the different fractions. The polymer material of the Mixed-D column packing was polystyrene-polydivinylbenzene copolymer of particle size $5 \mu \mathrm{m}$; the range of porosity gave the linear range between elution time and log molecular mass for polystyrene standards from 580 to $200000 \mathrm{u}$ in toluene eluent. 


\subsection{Fractionation}

Quantitative separations of the four samples were achieved using a column chromatography method on silica, $1 \mathrm{~g}$ of the sample was added to $5 \mathrm{~g}$ of silica and placed on top of $10 \mathrm{~g}$ of silica in an open column and held on a glass frit. Elution was by pentane $(2 \times 50 \mathrm{~mL})$, toluene $(100 \mathrm{~mL})$, acetonitrile (100 mL), pyridine (100 mL), 1-methyl-2-pyrrolidinone $(100 \mathrm{~mL})$ and water $(100 \mathrm{~mL})$. This followed previous column chromatography fractionations $[6,20,21]$ to isolate the largest molecular fractions of coal liquids. All the fractions were examined using the Mixed-D column with NMP eluent to observe the aromatics although the comparisons are limited here to the pentane and toluene fractions.

\subsection{Mass Spectrometry}

The pentane and toluene fractions of petroleum residue, coal tar pitch, coal digest and low temperature tar were examined using a high-temperature GC column from SGE and supplied by Jones Chromatography, UK; a 25 m HT-5 column of diameter $0.32 \mathrm{~mm}$ id, film thickness 0.1 micrometre, used with a Finnigan MAT TSQ700 mass spectrometer coupled via a heated transfer line to a Varian $3400 \mathrm{GC}$. The column temperature program was from $40^{\circ}$ (held $4 \mathrm{~min}$ ) to $350^{\circ}$ at $10^{\circ} \mathrm{min}^{-1}$ (held $20 \mathrm{~min}$ ), total time $53 \mathrm{~min}$. Mass spectrometer settings were: scanning range $\mathrm{m} / \mathrm{z} 50-850$, cycle time $1.5 \mathrm{~s}$, electron energy $70 \mathrm{eV}$.

\subsection{UV Fluorescence Spectroscopy}

The procedure has been described elsewhere [22]. The Perkin-Elmer LS50 luminescence spectrometer was set with a slit width of $25 \mathrm{~nm}$, to scan at $240 \mathrm{~nm} \mathrm{~min}^{-1}$; synchronous spectra were acquired at a constant wavelength difference of $20 \mathrm{~nm}$. A quartz cell with $1 \mathrm{~cm}$ path length was used. The spectrometer featured automatic correction for changes in source intensity as a function of wavelength. Emission, excitation, and synchronous spectra of the samples were obtained in NMP for all of the fractionation samples; only synchronous spectra are shown. Solutions were diluted with NMP to avoid self-absorption effects: dilution was increased until the fluorescence signal intensity began to both decrease in intensity and the relative intensities of the different maxima in the spectra ceased to change.

\section{RESULTS AND DISCUSSION}

The elemental analyses in Table 1 show that the petroleum residue has a similar $\mathrm{C}$ content as the coal digest but less than the pitch and more than the low temperature tar; it contains more hydrogen and much less oxygen than any of the coal tars. Also the $\mathrm{N}$ content is half that of the lowest $\% \mathrm{~N}$ of the coal derived tars. Therefore, the molecular structures present in the petroleum residue would be expected to be much less polar than those of the coal tars. This interpretation is borne out by the fraction weights recovered from column chromatography. The proportion of the petroleum residue eluted in pentane was $68.6 \%$, with only $21.2 \%$ of pitch, $42.1 \%$ of coal digest and $36.2 \%$ of the low temperature tar in this solvent. Including the fraction eluted in toluene brings these totals to $74.4 \%$ of petroleum residue, $47.4 \%$ of pitch, $52.2 \%$ of coal digest and $55.8 \%$ of low temperature tar. The mass balances recovered from the column showed that only $3 \%$ of the petroleum residue was lost, while losses from pitch and coal digest were approximately $14 \%$, with $16 \%$ of low temperature tar lost. These losses are not completely in line with the heteroatom contents of the samples, but it seems likely that the more polar (and/or high mass) components of the samples were retained on the silica. Also, the coal digest contained the recycle solvent used to dissolve coal and this solvent comprised mainly small molecules such as those of anthracene oil and hydrogenated PAH from continual recycling through a hydrogenation stage. We have shown elsewhere [23] that the trace metal contents of the coal tars were preferentially held in the pyridine-insoluble material of the tars and also held on the silica column packing.

The size exclusion chromatograms of the seven fractions of the petroleum derived sample are shown in Figure 1. The equivalent chromatograms for the coal samples (not presented) showed differences compared with each other and Figure 1. Most of the chromatograms for the different fractions of each sample showed bimodal distributions, separated by a valley of approximately zero intensity, with some early eluting material and some later-eluting, smaller-sized components.

The focus of this work is on the aromatic (NMP-soluble) components of the two pentane fractions and the toluene fraction. The first pentane-soluble fractions are compared in Figure 2a, while the second pentane-soluble fractions are compared in Figure 2b. The four toluene-soluble fractions are compared in Figure 2c. In each case the aromatics from the petroleum residue eluted before the coal tar fractions, indicating them to be of larger size than the coal derived aromatics. In addition, the peaks of the second pentane fractions and the toluene fractions shifted to earlier elution times compared with the first pentane fractions, again indicating that the aromatics became of larger size in the subsequent fractions. The coal digest chromatograms show some late eluting components attributable to the recycle solvent that did not all elute with the first pentane fraction. The petroleum residue, coal digest and low temperature tar contained alkanes and their characterization has been described previously [6]; these aliphatic materials were not detected by SEC in the present work using NMP as eluent and UV-absorbance as the detection method. 
TABLE 1

Elemental analyses and fraction weights from column chromatography

\begin{tabular}{|c|c|c|c|c|}
\hline & Petrox & Pitch & Coal Digest & LTT \\
\hline$\% \mathrm{C}$ & 86.8 & 91.4 & 85.9 & 82.3 \\
\hline$\% \mathrm{H}$ & 13.0 & 4.1 & 6.8 & 7.8 \\
\hline$\% \mathbf{N}$ & 0.4 & 1.3 & 0.8 & 0.9 \\
\hline$\% \mathrm{~S}$ & - & 0.8 & - & - \\
\hline$\% \mathrm{O}$ & - & $2.4^{+}$ & $6.6^{+}$ & $9.0^{+}$ \\
\hline Fractions* & Wt $\%$ & Wt $\%$ & Wt $\%$ & Wt $\%$ \\
\hline Pentane 1st & 50.7 & 3.8 & 12.4 & 10.5 \\
\hline Pentane 2nd & 18.0 & 17.4 & 29.6 & 25.7 \\
\hline Toluene & 5.7 & 26.5 & 10.1 & 19.6 \\
\hline Acetonitrile & 1.7 & 5.2 & 3.1 & 13.7 \\
\hline Pyridine & 2.5 & 15.3 & 17.5 & 4.0 \\
\hline NMP & 6.2 & 15.1 & 8.5 & 4.3 \\
\hline Water & 11.3 & 2.8 & 5.1 & 6.6 \\
\hline SUM & 97.0 & 86.1 & 86.4 & 84.4 \\
\hline \multicolumn{5}{|c|}{ Low-mass SEC peak evaluation vs polystyrene calibration } \\
\hline SEC & Peak/upper mass & Peak/upper mass & Peak/upper mass & Peak/upper mass \\
\hline 1st pentane & $240 / 660 \mathrm{u}$ & $200 / 400 \mathrm{u}$ & $200 / 660 \mathrm{u}$ & $200 / 1040 \mathrm{u}$ \\
\hline 2nd pentane & $440 / 3920 \mathrm{u}$ & $250 / 1010 \mathrm{u}$ & $200 / 1010 \mathrm{u}$ & $200 / 1680 \mathrm{u}$ \\
\hline Toluene & $700 / 10800 \mathrm{u}$ & $300 / 1680 \mathrm{u}$ & $240 / 2360 \mathrm{u}$ & $240 / 2360 \mathrm{u}$ \\
\hline \multicolumn{5}{|c|}{ Carbon range of n-alkanes determined by HT-GC-MS } \\
\hline 1st pentane & $17-44$ & none & $16-26$ & $16-40$ \\
\hline 2nd pentane & $31-41$ & none & none & none \\
\hline Toluene & none & none & none & none \\
\hline
\end{tabular}

* Material soluble in the solvents shown, by sequential elution.

+ Oxygen by difference, including sulphur if not determined separately.

- Not determined.

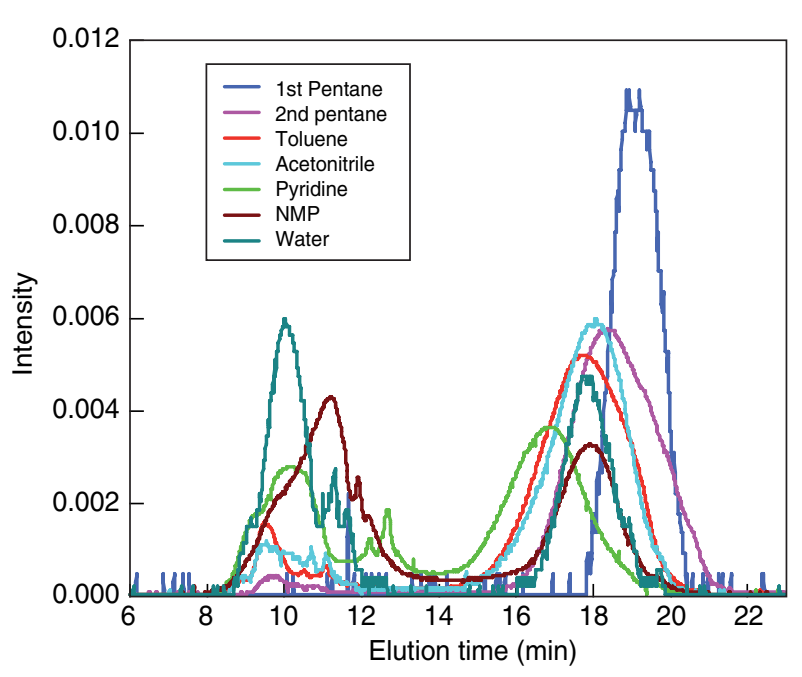

Figure 1

Size exclusion chromatograms of the seven fractions of the petroleum residue at $350 \mathrm{~nm}$ UV absorbance on the Mixed-D column. Fractions are: series 1-1st pentane, series 2-2nd pentane, series 3-toluene, series 4-acetonitrile, series 5-pyridine, series 6-NMP, series 7-water.
The fractions discussed here are of low polarity because the solvents used, pentane and toluene, are unable to displace polar molecules from adsorption on the active polar sites of the silica column. However, the present fractions soluble in pentane and toluene all showed an early eluting peak in SEC of material excluded from the column porosity. This is often associated [3] with the formation of aggregates of small polar molecules but in our use of SEC, there is no evidence for the formation of aggregates [1].

The presence of components excluded from the porosity of the SEC column, eluting between 9-13 min may be interpreted as showing the presence of large molecules, and/or possibly indicating the presence of three-dimensional structures or conformations (eluting earlier than would be warranted by their molecular masses alone) rather than of aggregates of the small polar components [1, 24, 25] of coal tars, identified by GC-MS analysis. The first pentane fraction chromatograms showed some low intensity excluded material in the coal derived liquids. The relative intensities of the excluded components increased in the second pentane and toluene fractions, with excluded material appearing in the 


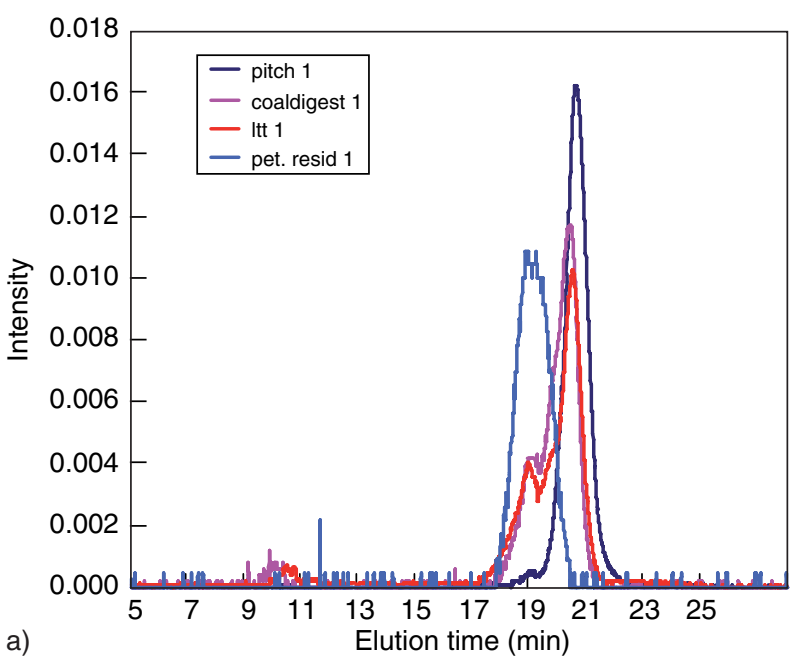

Figure 2a

Size exclusion chromatograms of the fractions: 1 st pentane fractions. Curves are: petroleum residue - light blue; pitch dark blue; coal digest - pink; low temperature tar - red. Detection by UV absorbance at $350 \mathrm{~nm}$.

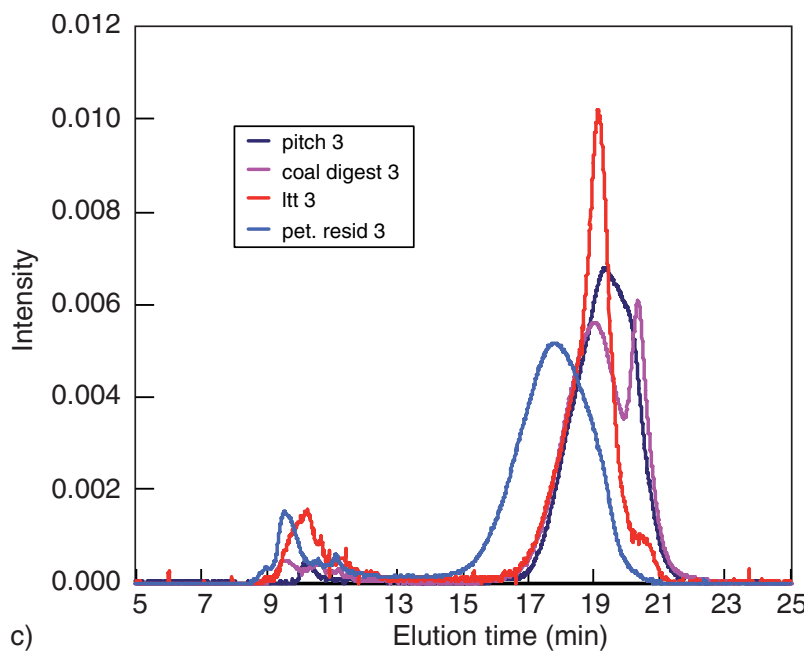

Figure 2c

Size exclusion chromatograms of the fractions: toluene fractions. Curves are: petroleum residue - light blue; pitch dark blue; coal digest - pink; low temperature tar - red. Detection by UV absorbance at $350 \mathrm{~nm}$.

second pentane and toluene fractions of petroleum residue. Given that these fractions of petroleum residue were composed of mainly non-polar components, it is unlikely that aggregation of polar components could provide these early eluting components [1]. The polystyrene molecular masses corresponding to the peak intensities of the chromatograms in Figure 2 together with the estimated upper mass limit of the retained peaks are listed in Table 1. The upper mass limit

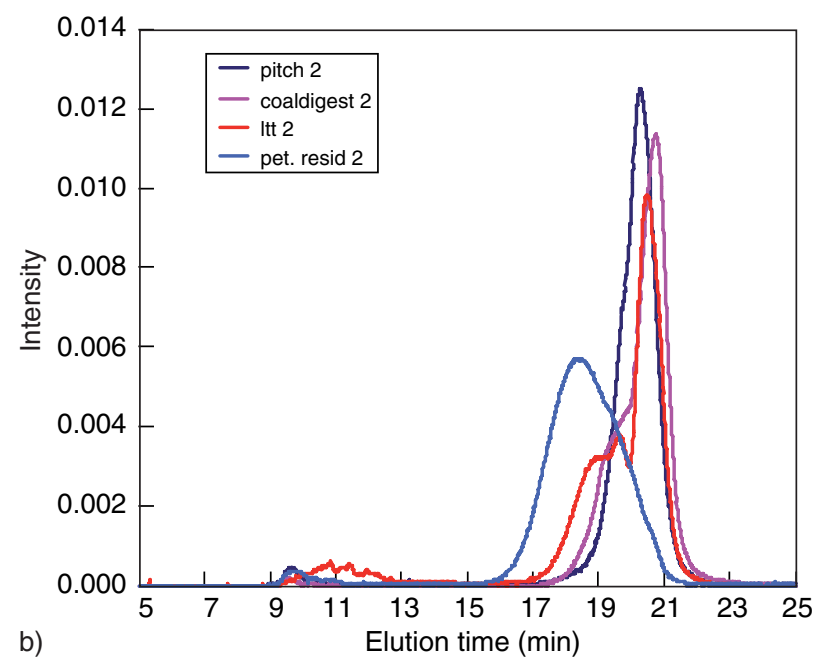

Figure $2 b$

Size exclusion chromatograms of the fractions: 2 nd pentane fractions. Curves are: petroleum residue - light blue; pitch dark blue; coal digest - pink; low temperature tar - red. Detection by UV absorbance at $350 \mathrm{~nm}$.

of the petroleum residue 1st pentane fraction (Fig. $2 a$ and Tab. 1) appears smaller than that of the low temperature tar, but this is probably a consequence of the small proportion of aromatics in this petroleum residue fraction. The GC-MS data below indicate that no aromatics were detected in this fraction although the SEC chromatogram indicates their presence at low concentration. In the 2 nd pentane and toluene fractions, the peak masses and upper mass limits of the petroleum residue exceeded those of the coal tars.

It is interesting to consider the findings on the molecular masses of the samples with structural information derived from synchronous UV-fluorescence spectroscopy. Figures 3a, $\mathrm{b}$, and $\mathrm{c}$ for the 1st and 2nd pentane soluble fractions and the toluene soluble fraction, respectively, clearly show that chromophores with the petroleum residue are consistently smaller than those of the coal derived tars. The first pentane solubles fraction of Figure 3 a showed smaller petroleum residue chromophores (maximum intensity $<340 \mathrm{~nm}$ ) than those of the coal tars. The latter gave maximum fluorescence intensity at about $360 \mathrm{~nm}$, corresponding to the smaller aromatics of the coal digest recycle oil and components of anthracene oil, probably smaller than pyrene, but with a range of chromophores showing signal up to $390 \mathrm{~nm}$.

In pentane-fraction 2, the pitch components of small mass, probably those detected by GC-MS, showed fluorescence within the same region as the main fluorescence of the petroleum residue at about $330 \mathrm{~nm}$. The longest wavelength fluorescence of the petroleum residue within this fraction occurred at the same wavelengths as the most intense region of the coal tars, $390 \mathrm{~nm}$. The fluorescence of the toluene soluble fractions showed that the petroleum residue and the low 


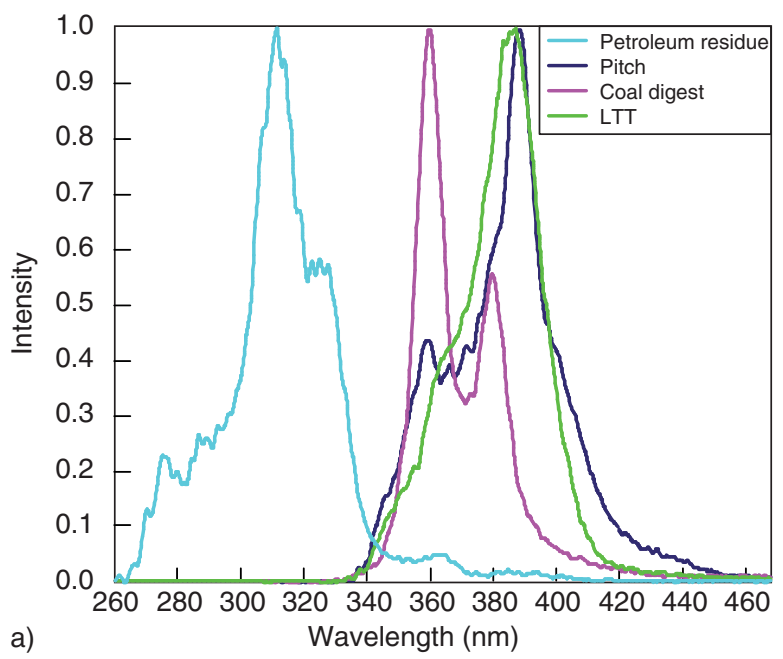

Figure 3a

Synchronous UV-fluorescence spectra of the fractions: 1st pentane fractions. Curves are: petroleum residue - light blue; pitch - dark blue; coal digest - pink; low temperature tar-green.

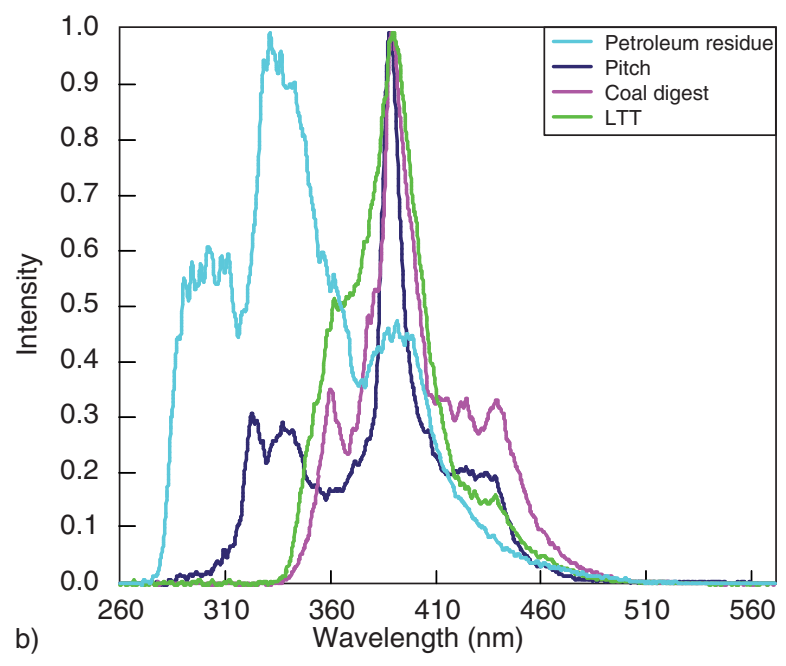

Figure 3b

Synchronous UV-fluorescence spectra of the fractions: 2nd pentane fractions. Curves are: petroleum residue - light blue; pitch - dark blue; coal digest - pink; low temperature tar-green.

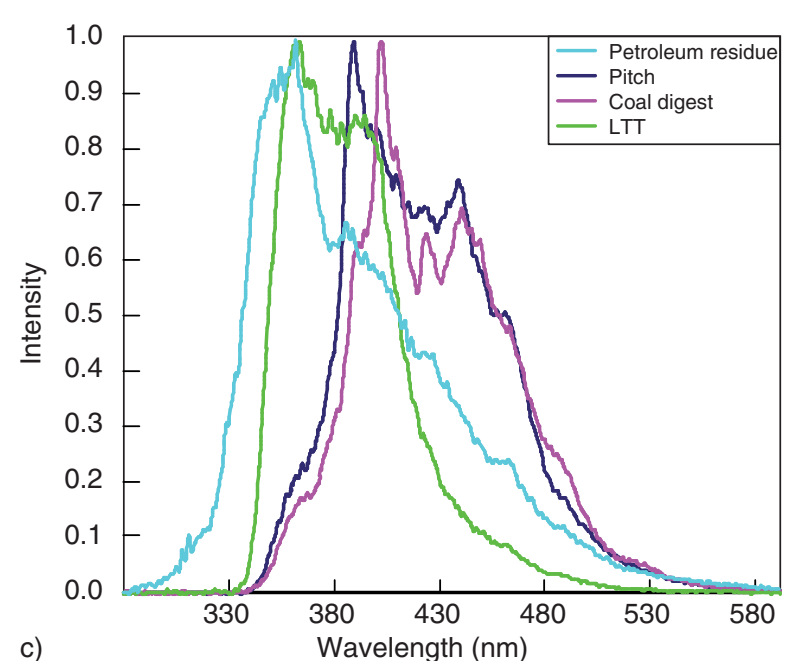

Figure 3c

Synchronous UV-fluorescence spectra of the fractions: toluene fractions. Curves are: petroleum residue - light blue; pitch dark blue; coal digest - pink; low temperature tar - green.

temperature tar had similar spectra while the pitch and coal digest were shifted to longer wavelengths but similar to each other. All four samples contained a wide range of chromophores, ranging from about 350 to $500 \mathrm{~nm}$, suggesting that the aromatic systems were more similar in these asphaltene-like fractions than in the pentane-soluble oils.

GC-MS total-ion chromatograms of the 1st pentane soluble fractions indicated the presence of a series of alkanes in the petroleum residue, low temperature tar and the coal digest (low intensity only) but none in the pitch. No significant aromatics were detected in the petroleum residue sample, but some were present and detected by SEC as a relatively lowintensity chromatogram. Only aromatic structures are observable in SEC as employed here, since the sample is eluted in NMP; however, there is no such restriction in analysing the samples by GC-MS.

In the 2 nd pentane soluble fractions, the petroleum residue contained mainly branched or cyclic alkanes with some lowintensity $n$-alkanes. The low temperature tar contained no alkanes but a very complex sequence of aromatics with alkyl chains. The coal digest 2 nd fraction, also contained no alkanes and a less complex sequence of aromatics, while the pitch contained only unsubstituted $\mathrm{PAH}$ up to $\mathrm{m} / \mathrm{z} 352$, tribenzopyrene isomers. Molecular mass numbers of aromatics are shown against the appropriate major peaks in the chromatograms of pitch and the coal digest. Those in the pitch are in general the unsubstituted PAH and methyl derivatives. Those in the 1st pentane fraction of the coal digest are hydrogenated aromatics rather than $\mathrm{PAH}$, but the $\mathrm{PAH}$ are more prominent in the 2 nd pentane fraction.

The toluene soluble fractions of all four samples contained no aliphatic components and only a few traces of high-mass aromatics of mass (m/z) 252 to 350 , able to pass through the high-temperature GC column. The majority of aromatics in the toluene fractions were beyond the molecular mass range of the GC. The structures of these aromatics are not determined.

The carbon ranges of the $n$-alkanes detected in these fractions have been summarized in Table 1. Total ion chromatograms are shown in Figure 4 for the aromatics of pitch, coal digest and low temperature tar. No aromatics were detected in the petroleum residue fractions apart from low intensity phenanthrene and alkyl phenanthrenes in the 

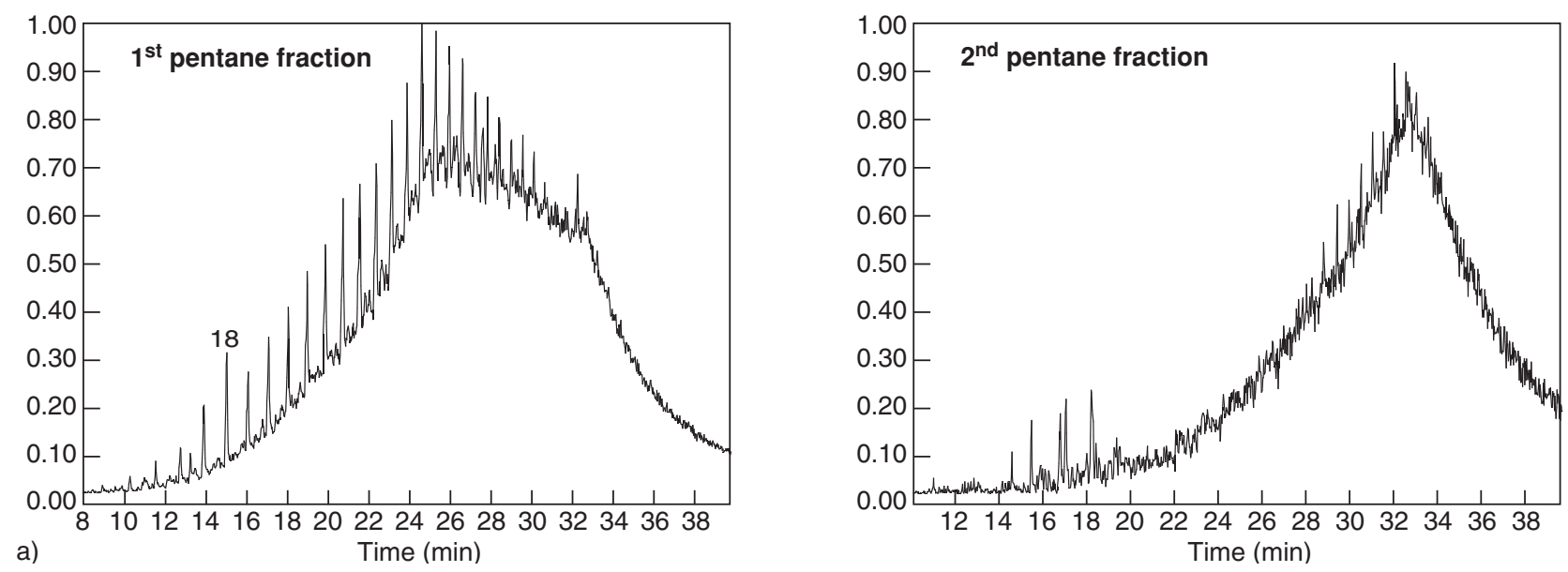

Figure $4 \mathrm{a}$

Total ion chromatograms from GC-MS of 1 st and 2 nd pentane fractions of petroleum resid. The $\mathrm{C}_{18} n$-alkane peak is marked in the upper chromatogram. Peaks from 15-18 min in the 2nd pentane fraction are phenanthrene and alkyl phenanthrenes.
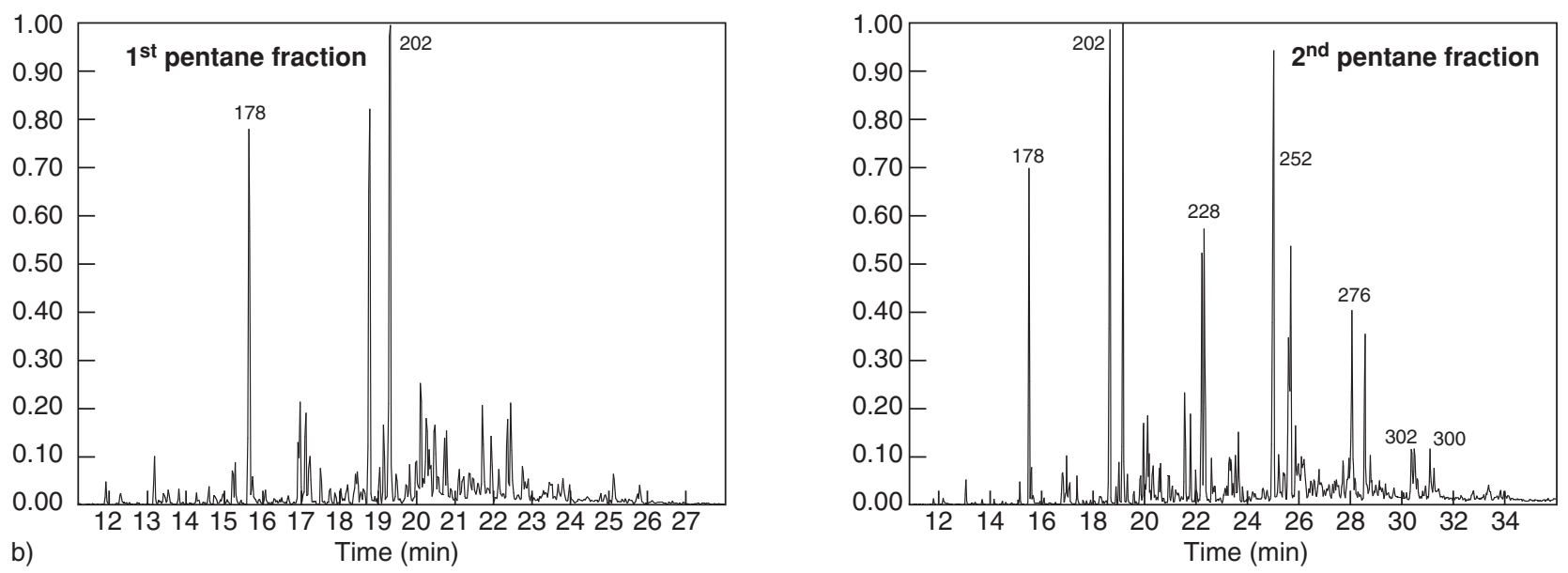

Figure $4 \mathrm{~b}$

GC-MS total ion chromatograms of 1st and 2nd pentane soluble fractions of pitch. Molecular mass numbers (m/z) of PAH shown above the peaks.
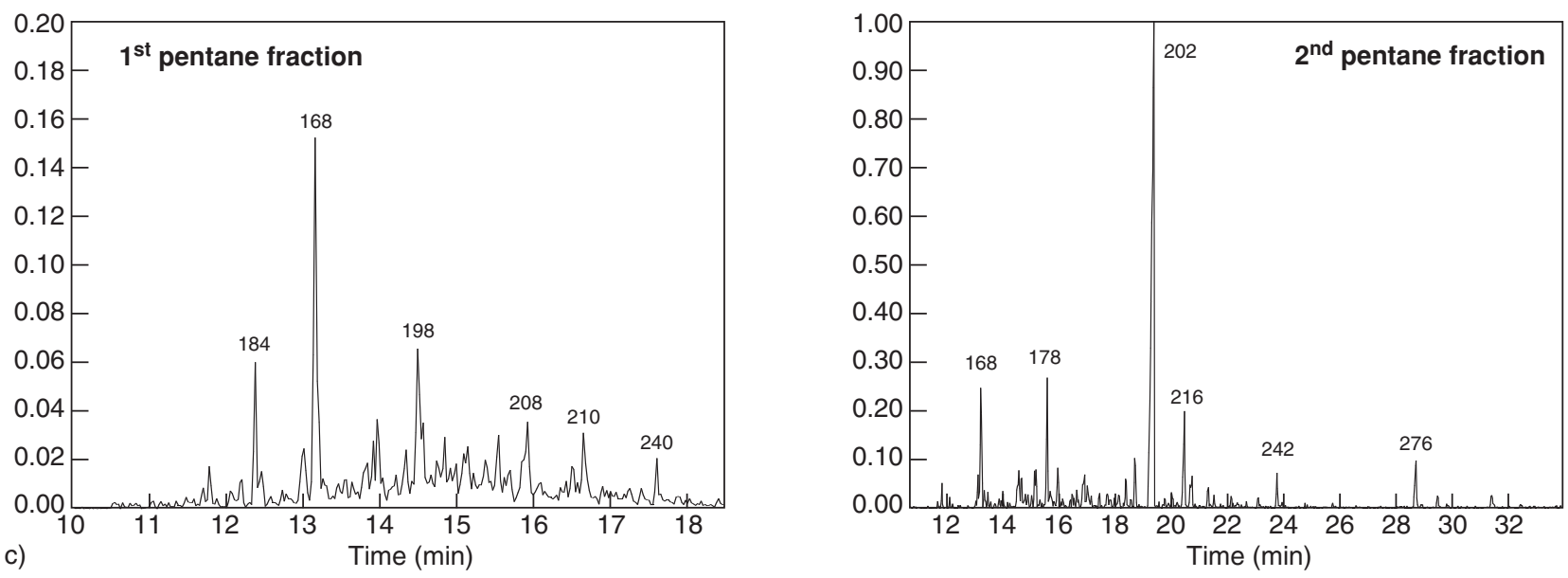

Figure 4c

Total ion chromatograms from GC-MS of 1st and 2nd pentane fractions of coal digest. Molecular mass $(\mathrm{m} / \mathrm{z})$ numbers of aromatics shown above peaks. 

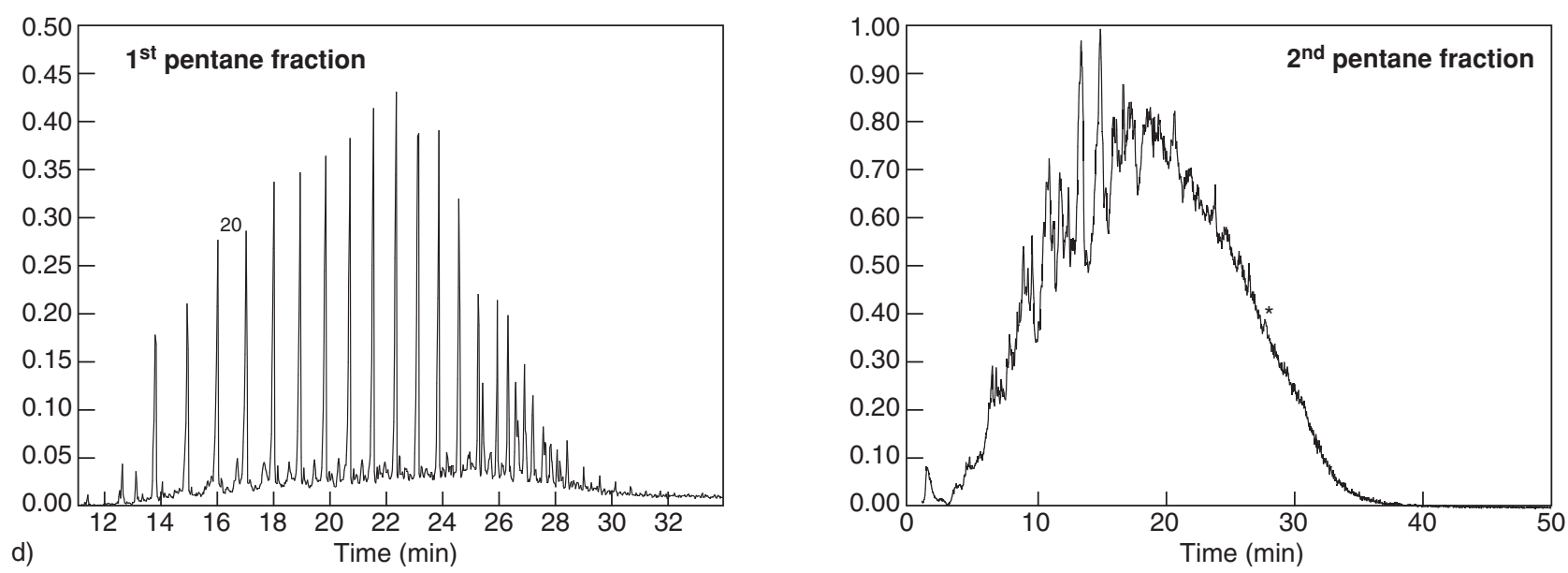

Figure 4d

Total ion chromatograms from GC-MS of 1st and 2nd pentane fractions of low temperature tar. The position of $\mathrm{C}_{20} n$-alkane in the upper chromatogram is marked.

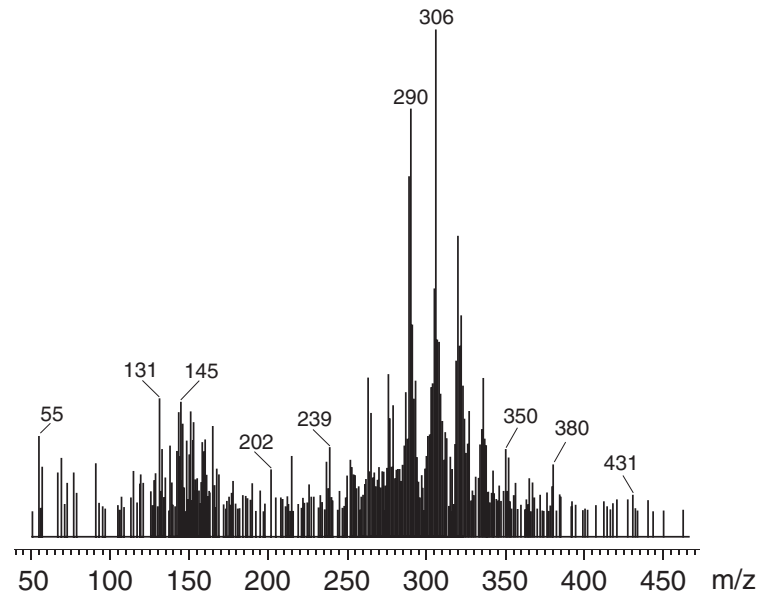

Figure 5

Mass spectrum of low temperature tar in Figure 4d, 2nd pentane fraction, for the peak marked by * at $30 \mathrm{~min}$.

2nd pentane soluble fraction. The mass spectrum in Figure 5 shows the complexity of the low temperature tar in the minor peak at $30 \mathrm{~min}$ of the 2 nd pentane fraction. We note that the polystyrene calibration for the Mixed-D column closely matched [19] the measured peak intensity masses (from LDand MALDI-MS) up to a little over $\mathrm{m} / \mathrm{z} 3000$ in the pitch sample. That range far exceeds the mass limits observed by GC-MS of the three coal tars used here.

\section{CONCLUSIONS}

The petroleum fractions in the three cases shown all elute from the SEC column earlier than the equivalent coal-derived fractions, showing that the aromatic, NMP soluble molecules of the petroleum residue were of larger molecular size than those of the coal liquids. However, the aromatic chromophores of the petroleum fractions were smaller (maximum fluorescence intensity at shorter wavelengths) than those of the coal liquids.

The fluorescence intensities of the coal liquids shifted towards the red end (longer wavelengths) of the spectrum in the order LTT $<$ digest $<$ pitch. This is the order of increasing thermal treatment and suggests that larger aromatic chromophores result from aromatization during thermal treatment. These data are consistent with the petroleum residue sample having experienced less extreme thermal treatment than the low temperature tar.

The GC-MS data showed that only the pentane-soluble components of these four samples are amenable to GC-MS; the larger aromatic molecules identified by SEC to be present are lost in the GC column. The aromatics observed in the coal liquids extended up to mass $(\mathrm{m} / \mathrm{z}) 352$ with few aliphatics present. Meanwhile, the aromatics detected in the petroleum residue were only small molecules such as phenanthrenes and the major aromatics were presumed to be too large or involatile to pass through the GC column.

Some of the material in the petroleum residue fractions was excluded from column porosity and eluted early from the SECcolumn. This is unlikely to be due to the presence of aggregates of polar molecules, since this residue is not very polar and contains only low hetero-atom concentrations. Similarly, the proportions of excluded material in the coal liquids do not fit with the heteroatom contents. Judged by hetero-atom content alone, the low temperature tar would have been expected to show the highest proportion of excluded material, among the present set of samples. However, this was not observed. It is likely that much of the excluded material, less able to penetrate column porosity, arises from changes from planar to three dimensional conformations of molecules, eluting at times appropriate for much larger molecular mass materials. 


\section{ACKNOWLEDGEMENT}

We thank Cedric Charpenteau for translating the abstract.

\section{REFERENCES}

1 Kandiyoti R., Herod A.A., Bartle K.D. (2006) Solid Fuels and Heavy Hydrocarbon Liquids: Thermal Characterisation and Analysis, Elsevier 2006, ISBN: 0-08-044486-5.

2 Herod A.A, Kandiyoti R., Bartle K.D. (2006) Comment on "Molecular size and weight of asphaltene and asphaltene solubility fractions from coals, crude oils and bitumen", Badre S., Goncalves C.C., Norinaga K., Gustavson G., Mullins O.C. (eds.), Fuel 85, 1-11, 1950-1951.

3 Mullins, O.C. (2007) Rebuttal to comment by professors Herod, Kandiyoti and Bartle on "Molecular size and weight of asphaltene and asphaltene solubility fractions from coals, crude oils and bitumen", Fuel 86, 309-312.

4 Hughey C.A., Rodgers R.P., Marshall A.G., Qian K., Robbins W.K. (2002) Identification of acidic NSO compounds in crude oils of different geochemical origins by negative ion electrospray Fourier transform ion cyclotron resonance mass spectrometry, Org. Geochem. 33, 743-759.

5 Qian K., Robbins W.K., Hughey C.A., Cooper H.J., Rodgers R.P., Marshall A.G. (2001) Resolution and identification of elemental compositions for more than 3000 crude acids in heavy petroleum by negative-ion microelectrospray highfield Fourier transform ion cyclotron resonance mass spectrometry, Energy Fuels 15, 1505-1511.

6 Al-Muhareb E.M., Karaca F., Morgan T.J., Herod A.A., Bull I.D., Kandiyoti R. (2006) Size Exclusion Chromatography for the unambiguous detection of aliphatics in fractions from petroleum vacuum residues, coal liquids and standard materials, in the presence of aromatics, Energy Fuels 20, 1165-1174

7 Pindoria R.V., Megaritis A., Chatzakis I.N., Vasanthakumar L.S., Lazaro M.J., Herod A.A., Garcia X.A., Gordon A., Kandiyoti R. (1997) Structural characterisation of tar from a coal gasification plant: comparison with a coke oven tar and a crude oil flash-column residue, Fuel 76, 101-113.

8 Deelchand J.-P., Naqvi Z., Dubau C., Shearman J., Lazaro M.-J., Herod A.A., Read H., Kandiyoti R. (1999) Planar chromatographic separation of petroleum residues and coalderived liquids, J. Chromatogr. A 830, 397-414 .

9 Suelves I., Islas C.A., Herod A.A., Kandiyoti R. (2001) Comparison of fractionation methods for the structural characterisation of petroleum residues, Energy Fuels 15, 429-437.

10 Li W., Morgan T.J, Herod A.A., Kandiyoti R. (2004) TLC of pitch and a petroleum vacuum residue - relation between mobility and molecular size shown by SEC, J. Chromatogr. A 1024, 227-243.

11 Domin M., Moreea R., Lazaro M.-J., Herod A.A., Kandiyoti R. (1997) Choice of extraction voltage and matrix in the MALDITOF mass spectrometry of coal tar pitch-pyridine insolubles, Rapid Commun. Mass Spectrom. 11, 638-645.
12 Lazaro M.-J., Herod A.A., Kandiyoti R. (1999) Comparison of the fractionation of a coal tar pitch by solvent solubility and by planar chromatography, Fuel 78, 795-801.

13 Herod A.A., Kandiyoti R. (1995) Fractionation by planar chromatography of a coal tar pitch for characterisation by size exclusion chromatography, UV-fluorescence and probemass spectrometry. J. Chromatogr. 708, 143-160.

14 Islas C.A., Suelves I., Li W., Morgan T.J., Herod A.A., Kandiyoti R. (2003) The unusual properties of high mass materials from coal derived liquids, Fuel 82, 1813-1823.

15 Islas C.A., Suelves I., Carter J.F., Herod A.A., Kandiyoti R. (2000) Pyrolysis-gc-ms of a coal extract and its fractions separated by planar chromatography: structural correlation with molecular mass. Rapid Commun. Mass Spectrom. 14, 1766-1782.

16 Herod A.J., Gibb T.C., Herod A.A., Shearman J., Dubau C., Zhang S.-F., Kandiyoti R. (1996) Planar Chromatography as a fractionation method for Mssbauer spectroscopy of a coal liquefaction digest, J. Planar Chromatogr. 9, 361-367.

17 Herod A.A., Millan M., Morgan T.J., Li W., Feng J., Kandiyoti R. (2005) Positive ion ESI-MS of acetone- and acetonitrile-soluble fractions of coal derived liquids, Eur. J. Mass Spectrom. 11, 429-442.

18 Islas C.A., Suelves I., Carter J.F., Li W., Morgan T.J., Herod A.A., Kandiyoti R. (2002) Pyrolysis-GC-MS of fractions separated from a low temperature coal tar: An attempt to develop a general method for characterising structures and compositions of heavy hydrocarbon liquids, Rapid Commun. Mass Spectrom. 16, 774-784.

19 Karaca F., Islas C.A., Millan M., Behrouzi M., Morgan T.J., Herod A.A., Kandiyoti R. (2004) The calibration of size exclusion chromatography columns: molecular mass distributions of heavy hydrocarbon liquids, Energy Fuels 18, 778-788.

20 Islas C.A. (2001) Chemical structure of the very high molecular weight constituents of coal, PhD Thesis, University of London.

21 Islas C.A., Suelves I., Li W., Morgan T.J., Herod A.A., Kandiyoti R. (2003) The unusual properties of high mass materials from coal derived liquids, Fuel 82, 1813-1823.

22 Li C.-Z., Wu F., Xu B., Kandiyoti R. (1995) Characterization of successive time/temperature-resolved liquefaction extract fractions released from coal in a flowing-solvent reactor, Fuel 74, 37-45.

23 Herod A.A., George A., Islas C.A., Suelves I., Kandiyoti R. (2003) Trace element partitioning between fractions of coal liquids during column chromatography and solvent separation, Energy Fuels 17, 862-873.

24 Millan M., Morgan T.J., Behrouzi M., Karaca F., Galmes C., Herod A.A., Kandiyoti R. (2005) The high mass component $(>\mathrm{m} / \mathrm{z} 10000)$ of coal tar pitch by MALDI-mass spectrometry and size exclusion chromatography, Rapid Commun. Mass Spectrom. 19, 1867-1873.

25 Al-Muhareb E., Morgan T.J., Herod A.A., Kandiyoti R. (2007) Characterisation of petroleum asphaltenes by Size Exclusion Chromatography, UV-fluorescence and mass spectrometry, Petrol. Sci. Technol. 25, 81-91.

Final manuscript received in August 2007

Copyright () 2007 Institut français du pétrole

Permission to make digital or hard copies of part or all of this work for personal or classroom use is granted without fee provided that copies are not made or distributed for profit or commercial advantage and that copies bear this notice and the full citation on the first page. Copyrights for components of this work owned by others than IFP must be honored. Abstracting with credit is permitted. To copy otherwise, to republish, to post on servers, or to redistribute to lists, requires prior specific permission and/or a fee: Request permission from Documentation, Institut français du pétrole, fax. +33147527078 , or revueogst@ifp.fr. 